УДК 531.383.01

DOI 10.17285/0869-7035.0028

\title{
В.Г. ПЕШЕХОНОВ
}

\section{ПЕРСПЕКТИВЫ РАЗВИТИЯ ГИРОСКОПИИ}

Современная гироскопия характеризуется значительным числом видов разработанных и разрабатываемых гироскопов. Доминируюшие позичии занимают волновые оптические гироскопы, реализующие релятивистский эффект Саньяка, и микромеханические вибрационные гироскопьы, принцип действия которых основан на эффекте Кориолиса. Одновременно частично сохраняют свои позиции высокоточные роторные механические гироскопы, в основе которых лежат приниипы динамики вращающегося твердого тела, и успешно продвигаются исследования по созданию гироскопов на принципах ядерной физики и квантовой оптики.

В статье рассматриваются состояние и перспективы развития гироскопов.

Ключевые слова: гироскоп, волновой оптический, твердотельный волновой, микромеханический, ядерно-магнитный, на волнах материи.

\section{Введение}

Гироскопия начала развиваться как раздел механики, и длительное время монопольное положение занимали механические гироскопы: роторные и вибрационные. На их основе были созданы различные гироскопические приборы и инерциальные навигационные системы (ИНС). Однако сложность и трудоемкость изготовления механических гироскопов и гироскопических систем, значительные массогабаритные характеристики и энергопотребление и, как следствие, высокая стоимость ограничивали применение средств гироскопии.

Развитие технологии управления движением все более широкого круга изделий требовало на порядок большего числа гироприборов, имеющих высокие эксплуата-

Пешехонов Владимир Григорьевич. Академик РАН, генеральный директор, АО «Концерн «ЦНИИ «Электроприбор» (С.-Петербург). Директор, Институт информационно-навигационных систем Университета ИТМО (С.-Петербург). Президент международной общественной организации «Академия навигации и управления движением».

Статья по докладу на Европейской конференции по управлению (European Control Conference - ECC 2020). 
ционные характеристики и относительно невысокую стоимость. Необходимо было перейти к крупносерийному производству гироскопов. Широкий поиск решения этой проблемы, предпринятый в 60-х годах прошлого столетия, привел к созданию качественно новой гироскопической техники - лазерных, волоконно-оптических, твердотельных волновых, микромеханических гироскопов. Ведутся исследования по созданию нового вида гироскопов, принцип действия которых основан на достижениях квантовой оптики.

Если учесть, что продолжают использоваться некоторые виды механических гироскопов (динамически настраиваемый, поплавковый, электростатический), то оказывается, что каждый диапазон точностных характеристик обеспечивают два или три вида гироскопов. В настоящей статье анализируются состояние разработки гироскопов и перспективы их применения.

\section{Волновые оптические гироскопы}

Лазерный гироскоп (ЛГ), имеющий дрейф нуля на уровне $10^{-2}$ град/ч и стабильный масштабный коэффициент, открыл возможность построения бесплатформенных инерциальных навигационных систем (БИНС) значительно более простых в производстве и более дешевых, чем ИНС на механических гироскопах. БИНС на ЛГ стали безальтернативной гироскопической навигационной системой в авиации, и благодаря этому впервые в истории гироскопии началось крупносерийное (на уровне сотен тысяч единиц) производство ЛГ. Так, за 20 лет (1995-2015 гг.) компания Honeywell произвела более 300 тысяч инерциальных измерительных модулей (триад) ЛГ.

Интерес к ЛГ вызвал волну исследований, направленных на снижение дрейфа нуля. Помимо стандартных для любого гироскопического прибора мер по снижению влияния на точностные характеристики вариаций тепловых и магнитных полей, исследовались пути решения специфических для ЛГ задач: уменьшения потерь при отражении оптического излучения от зеркал, образующих оптический резонатор, и методов вывода из полосы захвата встречных волн. В результате удалось снизить дрейф до $10^{-3}$ град/ч при приемлемых габаритах ЛГ. Основным препятствием для дальнейшего снижения случайного дрейфа стали средства преодоления эффекта захвата встречных волн: механические (вибрационная подставка) и электрооптические (на эффектах Зеемана и Фарадея).

Анализ потока публикаций по ЛГ показывает, что он достиг максимума во второй половине 80-х годов и с тех пор снижается. Статьи и доклады по тематике ЛГ посвящены в настоящее время сугубо частным вопросам. ЛГ занял нишу значений дрейфа нуля $10^{-1}-10^{-3}$ град/ч, и ожидать расширения этих границ не приходится. Впрочем, этот диапазон наиболее востребован в гироскопии, и ЛГ остается доминирующим гироскопом.

Другой гироскоп, принцип действия которого, как и ЛГ, основан на релятивистском эффекте Саньяка, - волоконно-оптический (ВОГ) - начал активно исследоваться на десятилетие позже ЛГ как гироскоп невысокой точности. БИНС на ВОГ появились только в текущем столетии. Три достоинства ВОГ позволили найти место для этой БИНС на рынке, который был уже насыщен БИНС на ЛГ. Во-первых, основные элементы и технологии ВОГ заимствованы из волоконно-оптических телекоммуникационных сетей, тщательно отработаны и имеют невысокую стоимость. 
Во-вторых, в ВОГ отсутствует эффект захвата встречных волн, и нет необходимости в устройствах, которые ограничивают точность ЛГ. Наконец, источник оптического излучения ВОГ находится вне оптического контура, тогда как в ЛГ газоразрядный источник оптического излучения находится в резонансном контуре, и по этой причине ВОГ потенциально надежнее ЛГ. Если добавить, что за счет увеличения длины оптического волокна в катушке ВОГ можно обеспечить уникальную чувствительность, то становится очевидной перспектива использования БИНС на ВОГ в тех случаях, когда необходимо обеспечить длительную высокоточную автономную работу гироскопической системы. К настоящему времени БИНС на ВОГ нашли широкое применение в морской технике и имеют хорошие перспективы в ракетно-космической. При этом необходимо учитывать, что ВОГ уступает ЛГ по стабильности масштабного коэффициента.

Анализ числа публикаций, посвященных ВОГ, не обнаруживает тренда к снижению, сегодня их в несколько раз больше, чем публикаций по тематике ЛГ. Главное направление исследований - поэтапное повышение точностных характеристик ВОГ. ВОГ становится гироскопом, не имеющим аналогов по перекрываемому диапазону точностей.

Перспективность ВОГ подтверждается большим числом компаний, которые занялись производством этого гироскопа. ВОГ тактического класса точности выпускают фирмы Германии, Китая, Нидерландов, России, США, Японии. Только фирма KVH (США) произвела более 90 тысяч ВОГ [1]. ВОГ навигационной точности производят фирмы Германии, Гонконга, Италии, Малайзии, России, США, Франции. Французская фирма iXBlue поставляет БИНС на ВОГ в 40 стран [2]. О производстве прецизионных ВОГ заявили фирмы Израиля, США, России и Франции.

Одним из путей повышения точностных характеристик БИНС на ВОГ стало использование автокомпенсации систематической составляющей дрейфа гироскопов. Реализована схема автокомпенсации однокоординатным вращением и исследована схема двухкоординатного вращения [3].

\section{Твердотельный волновой гироскоп}

Эффект инертности упругих волн во вращающемся осесимметричном теле был открыт на тридцать лет раньше эффекта Саньяка, но исследования возможности создания гироскопа на этом принципе $[4,5]$ начались на двадцать лет позже реализации первого ЛГ. С тех пор созданы твердотельные волновые гироскопы (ТВГ) средней и высокой точности на основе кварцевого полусферического резонатора и низкой точности с использованием металлического резонатора. Производство ТВГ высокой точности ведут фирмы США и Франции.

Первый высокоточный ТВГ был создан фирмой Northrop Grumman (США) для космических применений [6]. Сочетание высоких точностных и уникальных эксплуатационных характеристик прибора 130Р (табл. 1) является неоспоримым преимуществом ТВГ, однако высокая стоимость пока ограничивает его применение. Вероятно поэтому не получила развития попытка использования этого гироскопа в гироинклинометрах, обеспечивающих буровые работы.

Важным достижением разработчиков ТВГ стало обеспечение автокалибровки дрейфа нуля и масштабного коэффициента в процессе эксплуатации гироскопа [7]. 
Сенсацией последних лет стало создание высокоточного ТВГ французской фирмой Safran Electronics\&Defence [8]. Точностные параметры прибора Ragys 20, нашедшего применение в инерциальной навигационной системе космического применения Space Naute, пока уступают параметрам прибора 130P (см. табл. 1), но уже заявлены значительно более высокие точностные характеристики [9].

\section{Параметры высокоточных ТВГ}

\begin{tabular}{|c|c|c|c|}
\hline \multicolumn{2}{|l|}{ Параметры } & Прибор 130Р & Прибор Ragys 20 \\
\hline Дрейф нуль-пункта & град/ч & 0,0005 & 0,005 \\
\hline Случайный дрейф & град $/ \sqrt{ } ч$ & 0,00006 & 0,0002 \\
\hline $\begin{array}{l}\text { Нестабильность масштабного } \\
\text { коэффициента }\end{array}$ & ppm & 1 & 1 \\
\hline Диаметр резонатора & мм & 30 & 20 \\
\hline Допустимое ударное воздействие & $\mathrm{g}$ & 3000 & 5000 \\
\hline $\begin{array}{l}\text { Допустимое вибрационное } \\
\text { воздействие с амплитудой }\end{array}$ & $\mathrm{g}$ & 18 & 27 \\
\hline & & $\begin{array}{c}\text { Наработка в космосе - } \\
\text { более } 30 \text { млн ч }\end{array}$ & $\begin{array}{l}\text { В космосе работают } \\
\text { более } 100 \text { гироскопов }\end{array}$ \\
\hline
\end{tabular}

\section{Микромеханический гироскоп}

Развитие систем управления движением - от игрушек до сложных транспортных систем - потребовало создания датчиков параметров движения, технология производства которых была бы массовой и обеспечивала минимальный критерий $\mathrm{SWaP}+\mathrm{C}$ (размеры, вес, энергопотребление и стоимость). Решением проблемы стало создание микромеханических гироскопов (ММГ) и акселерометров (ММА).

Технология ММГ основана на процессах производства микроэлектроники (но с характерными размерами порядка 10 мкм), и его вибрационная система является своеобразным чипом, сопоставимым по габаритам, весу, энергопотреблению и стоимости с большой интегральной схемой. ММГ - первый гироскоп, пригодный для массового производства и использования.

Разработка ММГ началась во второй половине 80-х годов прошлого столетия, и уже через пятнадцать лет мировой рынок был насыщен гироскопами тактического класса точности. Дальнейшее развитие пошло по пути повышения точностных характеристик ММГ. Усилиями многих фирм в последнее десятилетие созданы гироскопы, обеспечивающие диапазон измерения угловых скоростей в пределах 200-1000 град/с,

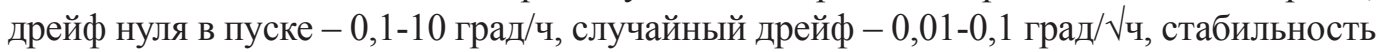
масштабного коэффициента - 300-2000 ppm.

На основании подобных ММГ созданы инерциальные измерительные модули (ИИМ), обеспечивающие кратковременное хранение навигационных данных с приемлемой для многих применений точностью. ИИМ, состоящий из триад ММГ и MMA, по критерию $\mathrm{SWaP}+\mathrm{C}$ близок к аппаратуре потребителя спутниковой навигационной информации. Интегрированная инерциально-спутниковая навигаци- 
онная система обеспечивает реализацию достоинств каждой из составных частей и компенсацию недостатков - спутниковый канал обеспечивает высокую точность определения координат места, погрешность определения которых не накапливается во времени, а ИИМ - кратковременное хранение навигационных данных при сбоях и кратковременных пропаданиях спутникового сигнала.

Производством ММГ занимаются фирмы Австралии, Великобритании, Германии, Норвегии, России, Франции, США, причем наряду с известными крупными компаниями успешно работают и стартапы.

\section{Перспективы развития гироскопии}

Современные исследования и разработки направлены на обеспечение минимального значения критерия $\mathrm{SWaP}+\mathrm{C}$ при достижении высоких точностных характеристик. Если этого удастся достичь, то гироскопия изменится радикально.

Среди гироскопов тактического класса точности безусловным лидером является ММГ. Этот гироскоп находится вне конкуренции по критерию $\mathrm{SWaP}+\mathrm{C}$, и такое положение сохранится на обозримую перспективу. Усовершенствование ММГ идет в части повышения точностных характеристик вплоть до низких навигационных точностей и в части повышения устойчивости к ударным воздействиям. В интересах повышения точностных характеристик разрабатываются многомассовые конструкции гироскопа (с двумя или большим числом вибрирующих пробных масс) и технология автокалибровки гироскопа в процессе эксплуатации. Радикальный путь преодоления «прилипания» пробной массы к неподвижному электроду при ударе предложен за счет уменьшения пробной массы без снижения чувствительности гироскопа [10].

Эволюция лазерного гироскопа направлена на снижение его массогабаритных характеристик путем создания микрооптических конструкций с использованием лазера Бриллюэна [11] или волн «шепчущей галереи» [12]. По точностным характеристикам экспериментальные образцы этих гироскопов соответствуют единицам град/ч, т.е. находятся на уровне современных серийных ММГ, а по критерию $\mathrm{SWaP}+\mathrm{C}$ безусловно уступают последним. В этих условиях прогнозировать широкое применение микрооптических гироскопов нет оснований, хотя отдельные ниши для их использования возможны.

Современные разработки ВОГ ориентированы на повышение точностных характеристик. Уже серийно выпускаются ВОГ, имеющие дрейф нуля на уровне $5 \cdot 10^{-4}$ град/ч [13], разрабатывается ВОГ эталонного класса, продемонстрировавший дрейф $3 \cdot 10^{-5}$ град/ч [14]. Эта величина близка к пределу точностных характеристик ВОГ, который оценивается на уровне $10^{-5}$ град/ч [15]. При достижении подобной точности БИНС на ВОГ может стать полноценной заменой прецизионной ИНС на электростатическом гироскопе, значительно превзойдя последнюю по критерию $\mathrm{SWaP}+\mathrm{C}$ и по устойчивости к механическим воздействиям.

Производители ТВГ расширяют область применения этого гироскопа. Уже разработаны БИНС на ТВГ для сухопутных и морских применений. Сообщается [16] о подтверждении достижимости дрейфа нуля на уровне $10^{-4}$ град/ч. Подобная БИНС безусловно выигрывает по сравнению с БИНС на ВОГ по критерию SWaP, но остается открытым вопрос о соотношении стоимости. Утверждение о готовности заменить ИНС на электростатическом гироскопе пока выглядит преждевременным. 
Несмотря на то что уже разработанные гироскопы имеют хорошие перспективы совершенствования, исследуется возможность создания гироскопов на новых физических принципах.

Серьезно продвинулась разработка гироскопа на эффекте ядерно-магнитного резонанса (ЯМГ). Возможность создания подобного гироскопа исследовалась еще в 60-е годы прошлого столетия, однако большие массогабаритные характеристики экспериментальных образцов и нерешенная проблема снижения влияния внешнего магнитного поля на пять порядков привели к тому, что это направление не получило развития.

В текущем столетии компания Northrop Grumman возобновила исследования и в результате ряда итераций (см. рис. 1) снизила объем ЯМГ до 10 см$^{3}$ [17]. Дрейф нуль-пункта составил порядка $10^{-2}$ град/ч. Детальный анализ факторов, определяющих точностные характеристики ЯМГ [18], показал, что этот результат близок к предельно достижимому. Учитывая, что принципиальным преимуществом ЯМГ является нечувствительность к механическим воздействиям и низкое значение критерия $\mathrm{SWaP}+\mathrm{C}$, можно ожидать, что БИНС на ЯМГ составит серьезную конкуренцию БИНС на ЛГ и на ВОГ в ряде применений.

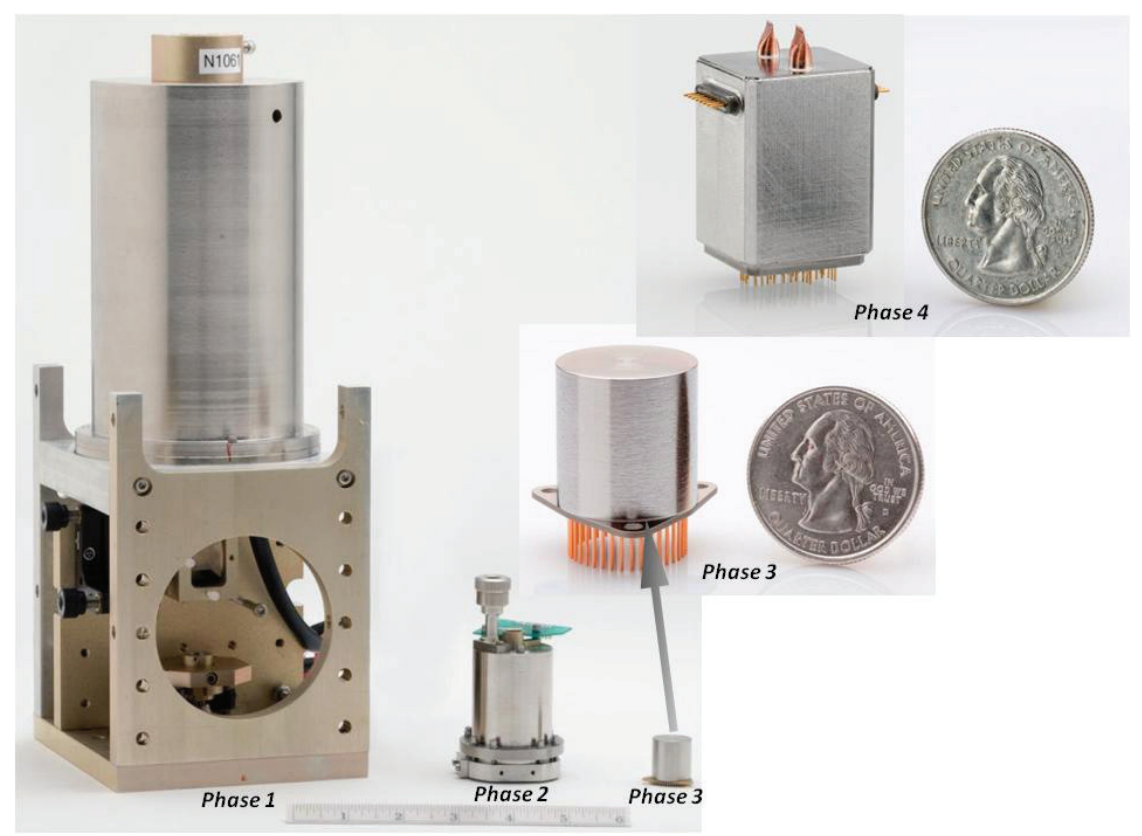

Рис. 1. Изменение размеров ЯМР-микрогироскопа: этап $1-3000 \mathrm{~cm}^{3}$; этап 2 - $55 \mathrm{~cm}^{3}$; этап $3-6 \mathrm{~cm}^{3}$; этап $4-10 \mathrm{~cm}^{3}$, герметизированный корпус [17]

Исследования гироскопа на волнах материи направлены на создание сверхпрецизионного прибора. Порождаемые в силу дуализма «волна-частица» потоком холодных атомов волны при построении интерферометра Саньяка теоретически дают выигрыш по сравнению с оптическими волнами на 10-11 порядков. Достаточно значительно меньшего выигрыша, чтобы создать сверхпрецизионный гироскоп. В настоящее время еще продолжаются физические исследования на лабораторных установках. Сообщалось [19], что создан демонстрационный образец датчика на холодных атомах, показавший уход по координатам 5 м в час. Но конструктивно дат- 
чик очень далек от требований критерия $\mathrm{SWaP}+\mathrm{C}$, и предстоит большая и длительная работа по доведению датчика до уровня чипа. Прогноз достижения требуемых характеристик в этих условиях сделать затруднительно, но потенциальная возможность приблизиться к точности спутниковой навигационной системы автономными средствами, не подверженными помехам и спуфингу, делает исследования в этой области актуальными.

\section{Заключение}

Современное состояние характеризуется доминированием волновых оптических гироскопов, на базе которых построены БИНС для авиационных, морских, космических и наземных применений. В этом классе гироскопов освоен диапазон точностей $10^{-1} \ldots 10^{-3}$ град/ч и завершаются работы по созданию ВОГ класса точности $10^{-4}$ град/ч.

Конкуренцию волновым оптическим гироскопам может составить волновой твердотельный гироскоп, широко используемый в космической технике США и Франции. Разрабатывается БИНС морского применения. ТВГ имеет безусловное преимущество перед волновыми оптическими гироскопами по массогабаритным характеристикам, но пока имеет более высокую стоимость.

Еще одним конкурентом в диапазоне средних и высоких навигационных точностей (случайный дрейф $10^{-2} \ldots 10^{-3}$ град/ч) может стать гироскоп на ядерном магнитном резонансе, разработка которого завершается. Безусловным преимуществом этого гироскопа является устойчивость к механическим воздействиям.

Лидером в тактическом диапазоне точностей является микромеханический гироскоп, выпускаемый массово. Реально расширение диапазона его точностных характеристик до низкой навигационной точности $\left(10^{-1}\right.$ град/ч).

Потенциально гироскоп сверхвысокой точности может быть создан на волнах материи (холодных атомах), но работы пока не вышли из физических лабораторий.

В этих условиях сохраняется прецизионный электростатический гироскоп, но по трем видам гироскопов (ВОГ, ТВГ и на волнах материи) ведутся работы на его замену. Остальные виды механических гироскопов если и используются, то только в ограниченных областях и количествах.

\section{Благодарность}

Автор признателен Б.С. Ривкину, «Аналитические обзоры» которого оказались чрезвычайно полезны при написании данной статьи.

\section{ЛИТЕРАТУРА}

1. https://www.kvh.com/Military-and-Government/Gyros-and-Inertial-Systems-and-Compasses/Gyrosand-IMUs-and-INS.aspx.

2. https://www.ixblue.com.

3. Степанов А.П., Емельянцев Г.И., Блажнов Б.А. Об эффективности модуляционных поворотов измерительного модуля БИНС на ВОГ морского применения // Гироскопия и навигация. 2015. №4 (91). С 42.

4. Журавлев В.Ф., Климов Д.М. Волновой твердотельный гироскоп. М.: Наука, 1985. 128 с.

5. Lynch, D.D., Vibration-induced drift in the hemispherical resonator gyro, Proc. of the Annual Meeting of the Institute of Navigation 23-25 June 1987, p. 34. 
6. Мейер Д., Розелле Д. Инерциальная навигационная система на основе миниатюрного волнового твердотельного гироскопа // Гироскопия и навигация. 2012. №3 (78). С. 45-54.

7. Trusov, A.A., et all., Continuously self-calibrating CVG system using hemispherical resonator gyroscopes, 2015 IEEE International Symposium on Inertial Sensors and Systems (ISISS) Proceedings, Hapuna Beach, HI, USA, 23-26 March 2015. DOI: 10.1109/ISISS.2015.7102362.

8. Делэйе Ф. Бортовая инерциальная система координат SpaceNaute ${ }^{\circledR}$ для европейской ракетыносителя «Ариан-6» на основе волнового твердотельного гироскопа // Гироскопия и навигация. 2018. №4 (103). C. 3-13.

9. https://www.safran-electronics-defense.com/naval-solutions/submarines/navigation-systems.

10. htpps:/www.i-micronews.com/mems-sensors/9751-nanusen-solvesthe-problem-of-stiction-in-memsinertial-sensors-by-going-smallerand-creating-nano-sensors-in- standard-cmos.html.

11. www.geo-matching.com/products/id4387-m-g364pdc0.html.

12. Maleki, L. et all., Sensitivity Limitations of a Resonant Microphotonic Gyroscope, IEEE Photonics Conference, 2016. DOI 10.1109/IPCon.2016.7831128.

13. https://ieeexplore.ieee.org/document/6851515.

14. Sanders, G.A. et all., Fiber optic gyro development at Honeywell, Proc. SPIE 9852, Fiber Optic Sensors and Applications XIII, 985207, 12 May 2016. DOI: 10.1117/12.2228893.

15. Лефевр Э.К. Волоконно-оптический гироскоп: достижения и перспективы // Гироскопия и навигация. 2012. №4 (79). С. 3-9.

16. Delhaye, F., HRG by Safran. The Game-changing Technology, 2018 IEEE International Symposium on Inertial Sensors and Systems (INERTIAL), 26-29 March 2018, Moltrasio, Italy, DOI:10.1109/ ISISS.2018.8358163.

17. Мейер Д., Ларсен М. Гироскоп на ядерном магнитном резонансе для инерциальной навигации // Гироскопия и навигация. 2014. №1 (84). С.3-13.

18. Вершовский А.К., Литманович Ю.А., Пазгалев А.С., Пешехонов В.Г. Гироскоп на ядерном магнитном резонансе: предельные характеристики // Гироскопия и навигация. 2018. №1 (100). С. 55-80.

19. Kramer, D., DARPA Looks Beyond GPS for Positioning, Navigation and Timing, Physics Today, vol. 67, № 10, doi: 10.1063/PT.3.2543.

Peshekhonov, V.G. (Concern CSRI Elektropribor, JSC, St. Petersburg; ITMO University, St. Petersburg) The Outlook for Gyroscopy, Giroskopiya i Navigatsiya, 2020, vol. 28, no. 2 (109), pp. 3-10.

Abstract. Modern gyroscopy is characterized by a great diversity of gyroscopes that have been and are being developed. Dominant positions belong to wave optic gyroscopes implementing the relativistic Sagnac effect, and micromechanical vibratory gyroscopes the operating principle of which is based on Coriolis effect. At the same time, high-precision rotor mechanical gyroscopes based on the principles of rotating solid body dynamics partially retain their position; also, the research of gyroscopes developed on the principles of nuclear physics and quantum optics is progressing successfully.

Current state and the prospects of gyroscopes development are discussed in this paper.

Key words: gyroscope, wave optic gyro, hemispherical resonator gyro, micromechanical gyro, nuclear magnetic resonance, gyro on matter waves.

Материал поступил 20.01.2020 